\title{
Os usos de stato e umori em $O$ príncipe uma leitura a partir de Gennaro Sasso
}

\author{
Luís Falcão
}

\section{SciELO Books / SciELO Livros / SciELO Libros}

FALCÃO, L. Os usos de stato e umori em O príncipe: uma leitura a partir de Gennaro Sasso. In: PINTO, F.M., and BENEVENUTO, F., comps. Filosofia, política e cosmologia: ensaios sobre o renascimento [online]. São Bernardo do Campo, SP: Editora UFABC, 2017, pp. 161-180. ISBN: 978-85-68576-93-9. https://doi.org/10.7476/9788568576939.0009.

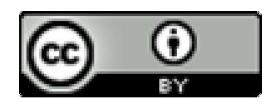

All the contents of this work, except where otherwise noted, is licensed under a Creative Commons Attribution 4.0 International license.

Todo o conteúdo deste trabalho, exceto quando houver ressalva, é publicado sob a licença Creative Commons Atribição $\underline{4.0}$.

Todo el contenido de esta obra, excepto donde se indique lo contrario, está bajo licencia de la licencia $\underline{\text { Creative }}$ Commons Reconocimento 4.0. 
Graduado em Ciências Sociais pela UFF (2008), em Economia pela UERJ (2009), Mestre (2010) e Doutor (2015) em Ciência Política pelo IESP, com período sanduíche na Università degli Studi di Milano (2013\2014). Atualmente é professor adjunto de Ciência Política da Universidade Federal Fluminense e do Programa de Pós-Graduação em Ciência Política da mesma instituição). Desenvolve pesquisas na área de Teoria Política Moderna com ênfase em Republicanismo, Maquiavelismo e Jusnaturalismo. É autor de Maquiavel, Montesquieu e Madison: uma tradição republicana em duas perpectivas (Rio de Janeiro: Azougue, 2013) 


\section{OS USOS DE STATO E UMORI EM O PRÍNCIPE: UMA LEITURA A PARTIR DE GENNARO SASSO ${ }^{1}$}

\section{Luís Falcão ${ }^{2}$}

Entre as inumeráveis contribuições aos estudos sobre Maquiavel, o século vinte observou a ascensão de um tema fundamental no pensador florentino que, até então, se encontrava, para dizer o mínimo, negligenciado pelos intérpretes. Tradicionalmente, marca-se a inflexão maquiaveliana pelo realismo, a percepção de que a análise política deve seguir os preceitos de mundo como é, como se mostra ao observador, e não, para seguir seu próprio vocabulário, a imaginação, isto é, a premissa do dever-ser em oposição ao ser. Todavia, nas últimas décadas, diversos especialistas inseriram ao modus operandi do realismo a percepção do conflito. Assim, nesse quesito,

\footnotetext{
${ }^{1}$ Este trabalho foi composto para uma comunicação oral no encontro "500 anos de O Príncipe: colóquio Maquiavel” realizado na UFMG entre os dias 17 e 19 de junho de 2013.

${ }^{2}$ Professor de Ciência Política da Universidade Federal Fluminense (UFF).
} 
Maquiavel estaria além de um autor que descreve o universo político como se mostra, mas supõe, com um arcabouço teórico que lhe é bem particular, que em todas as cidades, em todas as agremiações humanas, existem conflitos. Vincular o conflito à condição humana não é exatamente uma peculiaridade do secretário de Florença, antes disso, é o reconhecimento explícito de que os conflitos podem ser produtores de boa ordenação política, do governo das leis em oposição ao governo dos homens e da liberdade.

Uma das contribuições mais profícuas nesse sentido é de Claude Lefort $(1972 ; 1979)$. Para o intérprete francês, há um substrato teórico que guia a percepção do conflito maquiaveliano que está ligado ao aspecto econômico da "luta de classes”, expressão empregada pelo próprio Lefort (1979, p. 142; cf. LEFORT, 1972, p. 488-531). Supondo um direcionamento analítico para a dimensão do poder, Maquiavel não estaria menos preocupado com o comércio e a propriedade do que com as leis e o governo. Assim, Lefort destaca o caráter constitutivo dos conflitos entre os grandes, que querem dominar, e o povo, que quer não ser dominado. A força da interpretação lefortiana foi e continua a ser enorme para os estudos maquiavelianos porquanto se entenda a aspiração de se conformar uma teoria não apenas generalizável, mas sobretudo fundante das próprias relações sociais de poder.

Um caminho alternativo de se pensar o conflito foi promovido por Gennaro Sasso (1993). Antes de supor uma teoria generalizável e essencialista da condição do conflito, ele propõe uma leitura que parte dos casos e especificidades dos momentos mais marcantes da obra de Maquiavel que trata do tema. Assim, para ele, torna-se paradigmático o contraste entre os exemplos empregados pelo próprio florentino. 
Não obstante o alto nível de detalhamento de sua contribuição, Sasso não pretende avançar, como faz Lefort, para uma teoria generalista. A questão se mostra interessante porque Sasso abre um caminho de análise do conflito maquiaveliano centrada nas condições de suas respectivas positividades e negatividades. Contudo, o intérprete italiano não visa destrinchar em Maquiavel os aspectos que simultaneamente unem o conflito dos diferentes umori com a capacidade de absorção deles pelo Stato. Diante dessa sugestão de Sasso, o presente trabalho pretende estudar a relação entre os usos de Stato e umori contrastada com o papel do príncipe na dinâmica política das cidades.

Em Machiavelli: la storiografia, Sasso percorre a argumentação maquiaveliana a respeito das distinções entre Florença moderna e Roma antiga, no intuito de compreender como o conflito político produziu resultados tão díspares. Partindo, assim, da assertiva de que os conflitos são consequências da diversidade dos humores, entre o povo e os grandes (SASSO, 1993, p. 169), Sasso debruça-se sobre a explicação. Duas são as formas pelas quais a matéria pode ter sua corrupção corrigida: pela vida social e pelas leis. A incompatibilidade dessas duas não apenas mantém a corrupção do corpo, mas também, o que parece mais grave, leva a cidade à violência. Interessante que seja o conflito dos humores a potência diretiva capaz de produzir a vida civil e as leis e, simultaneamente, destruí-las. Não obstante os acidentes serem uma das formas que caminham para um ou outro lado, o estudo paulatino de Roma e Florença permite identificar a variedade institucional. 
Diferentemente da cidade eterna, Florença não possuía uma divisão binária dos humores, de modo que existiam muitos grupos políticos em torno das mesmas querelas (SASSO, 1993, p. 179). Além disso, os conflitos eram entre nobres, e não entre os nobres e o povo. Também se faziam privada e ambiciosamente, ao invés de público e moderado (SASSO, 1993, p. 183-186). Tal infortúnio da cidade de Maquiavel jamais permitiria uma ordenação que produzisse unidade, uma vez que a produção, reprodução e multiplicação das facções desconcentravam a unidade em torno do poder político (SASSO, 1993, p. 189). De uma ponta à outra da narrativa, Sasso expõe um argumento que se inicia com os humores e termina com o Estado. Deixa entrever que, por um lado, os humores são uma potência neutra que levam à grandeza ou ruína, por outro, a necessidade de os conflitos convergirem para um único ponto. Entretanto, nada há de referências, nessa argumentação, a O Príncipe . $^{3}$.

Duas recentes edições críticas de O Príncipe, (INGLESE, 1996; RUGGIERO, 2010) apresentam notas críticas fortemente orientadas para a preocupação com o Stato e seus usos. A respeito do conflito político, Ruggiero (2010, p. 113) comenta longamente, a partir do capítulo IX, que a interpretação da política maquiaveliana pode ser lida na chave do conflito e, acrescenta páginas à frente, que o problema dos Stati - repúblicas ou principados - pode ser sintetizado nas boas armas da milícia e nas boas leis. Isso acrescenta um elemento novo àquela explicação oferecida por Sasso: a força militar. A união das duas análises pode sugerir uma necessária unidade

\footnotetext{
${ }^{3}$ No presente trabalho, para referenciar a obra O Príncipe, usaremos a abreviatura Principe, seguida do capítulo.
} 
entre os elementos da civilidade social e a milícia: as leis. Assim, uma leitura plausível seria a de que as leis conformariam o substrato do conflito dos humores institucionalizados com a violência estatal.

Dialogando mais detidamente com possíveis referências aos antigos e humanistas, Inglese atém-se igualmente ao problema do uso de Stato quando, por exemplo, afirma que o uso de imperio significa "poder político" e stati, domínio (Principe, I). Apesar de, comentando o capítulo terceiro, o estudioso revelar a incompatibilidade entre a política e a violência, ambas são modos que ensejam domínios e, ao tratar do nono capítulo, apresenta uma análise interessante. A partir do momento em que Maquiavel expõe os dois humores (Principe, IX), Inglese afirma que deles emergem duas "formas políticas": o principado e a liberdade. $\mathrm{O}$ mesmo príncipe que se sustentava na violência do Stato até então, passa a ser identificado com a política em oposição à liberdade. Aqui, não parece que Inglese reconheça essas duas facetas do Stato (violenta e política) como áreas distintas de ação, embora o tenha feito anteriormente.

Antes de uma contradição dos comentários de Inglese, pode-se observar o assunto de outro ângulo. Durante o desfecho dos primeiros 11 capítulos e introdução da sequência dos argumentos, Maquiavel escreve: "Os principais fundamentos que têm todos os Estados, sejam novos, velhos ou mistos, são as boas leis e as boas armas" (Principe, IX; tradução nossa) $)^{4}$. Sobre essa passagem, Inglese comenta:

Leis e armas são um lugar comum, mas que se refere a um aspecto essencial do pensamento de Maquiavel,

\footnotetext{
4 " $E$ ' principali fondamenti che abbino tutti li stati, cosí nouvi come vecchi o misti, sono le buone legge e le buone arme".
} 
que funda a potência de um Estado sobre a eficácia de sua constituição em relação ao inevitável conflito entre os 'humores' dos grandes e do povo" (Principe, XII; tradução nossa).

Fica claro que a compreensão de Inglese do uso maquiaveliano de Stato unifica o conflito dos humores com a potência das armas (BARON, 1992).

Focando a questão exclusivamente nos primeiros 11 capítulos de $O$ Príncipe, ela pode ser abordada a partir da seguinte pergunta: quais são as situações em que o príncipe (ou o principado) desfruta da unidade entre umori e Stato?

O objetivo desse trabalho é abordar a dimensão conceitual da política em $O$ Príncipe. Começando pelo uso do termo, a palavra política, ou suas derivações, não se encontra na obra. Por outro lado, a utilização de Stato pode significar, na maior parte das vezes, um correspondente à altura. Procuraremos argumentar que a teoria dos humores, do povo e dos grandes, reflete a dinâmica política, sustentada na percepção maquiaveliana de que em todas as cidades existem governantes e governados, fundamento do Estado moderno (ESPOSITO, 1984, p. 185; MANSFIELD, 1998, p. 288-294; VIROLI, 1999, p. 152-161). Além disso, o processo de resistência à dominação se dá na esfera dos conflitos de humores. Desse modo, os tumultos (tumulti) são inerentes ao processo político e sua realização é o fundamento da boa ordenação. A contrariedade inerente a esses dois conceitos se realiza na dinâmica dos acontecimentos que se sucedem, o que torna inócua qualquer dimensão transcendente da política. Diante dessa perspectiva, 
a separação de política e moralidade, que ficou conhecida como realismo político, enseja a negação de qualquer parâmetro político que não seja estritamente humano (BIGNOTTO, 1991, p. 87; STRAUSS, 1978, p. 11; 36; CHABOD, 1958, p. 190; SKINNER, 1996, p. 155).

Na dedicatória de $O$ Príncipe, o fundamento do Estado moderno já está inserido nos dois lugares descritos: o baixo e o alto (Principe, Dedicatória). Para se compreender um dos lados é preciso observá-lo do ponto de vista oposto. A metáfora geográfica de que de cima se pode ver melhor aqueles que estão no baixo, e vice-versa, mas que do lugar onde se está não se pode ver com precisão a si mesmo, reflete um conhecimento político parcial. Além do fato de os dois lugares já estarem subjacentes na análise, os governantes e os governados, cada um deles tem melhor percepção de seu oponente. Por isso, ocorrem os conflitos e é essa tensão entre os que governam e os que são governados que põe a política em andamento (STRAUSS, 1978, p. 19). Do reconhecimento tácito do pressuposto dos dois lugares políticos emerge a interpretação de que o lócus dos tumultos é o Estado moderno. Ao sustentar a dinâmica política, o Stato absorve as disputas inerentes a todas as cidades (Principe, IX). Nesse sentido, os que governam ocupam esse lugar, os que são governados buscam obliterar a vontade dos governantes. Nessa síntese promovida pelo uso do termo Stato, ele se torna o substitutivo lógico de política. Em outros termos, a política moderna depende, fundamentalmente, do Stato, porque assegura a existência de governantes e governados, característica essa que desembocará na teoria dos humores e, consequentemente, na compreensão de que a política é conflito (BERARDI, 1975). 
Com o uso de Stato, Maquiavel coloca sob seu domínio (imperio) as características centrais dos Estados modernos (população, território, dinâmica interna, ação coercitiva, poderio bélico etc.), porém nem toda atividade do Stato é atividade política. A ação política do Stato se limita à capacidade de absorção dos umori, ou seja, a unidade entre umori e Stato é o fundamento da dinâmica política em Maquiavel. Dependendo das circunstâncias, uma cidade pode ou não estar submetida a uma lógica política, contudo sempre estará embebida de alguma forma de dominação.

A distinção entre a ação política e a pura violência dos governantes (STRAUSS, 1978, p. 57) pode ser mais precisamente identificada nos casos ambíguos. Os principados e, em especial, os príncipes novos, são retratados de muitas maneiras, mas apenas um deles é capaz de sustentar a contradição dos humores: o principado civil (BIGNOTTO, 1991, p. 116). Maquiavel define este regime pelo modo de aquisição do poder, pelo favor de seus cidadãos torna-se príncipe (Principe, IX), e não por meios violentos. Quando uma república enfrenta um momento de crise (Discorsi $i^{5}$, I, 17 e 18), uma solução possível é eleger um dos cidadãos para príncipe, este é o principado civil, um regime político por excelência. Não obstante a generalização observada pelo uso de cidadãos (cittadini), diferentemente de súditos, como até então usava, apenas um dos dois humores pode conduzir um cidadão ao principado. Isso significa que não é um consenso de todos os cidadãos, mas é quando um dos dois lados reconhece a necessidade de um príncipe e consegue implementar sua vontade. Mesmo que o

\footnotetext{
5 Abreviatura usada para referenciar a obra Discursos sobre a primeira década de Tito Lívio, em seguida estão indicados o livro e o capítulo utilizados.
} 
favor seja feito pelo povo ou pelos grandes, e não por ambos, importa destacar que existe uma tensão entre esses dois grupos para além do fato de que o povo deseja não ser comandado e os grandes desejam comandar (Principe, IX). Reside aqui o fundamento verdadeiramente republicano: em todas as cidades se encontram dois humores. Ocorre que na maioria dos principados estes humores estão adormecidos, pela tradição (Principe, II), pela força externa (Principe, III), pelo caráter absoluto do governo (Principe, IV), pela falta de liberdade (Principe, V), pela grandeza da virtù individual que ofusca a coletiva (Principe, VI), pela vontade da fortuna (Principe, VII) ou pela força (Principe, VIII). No principado civil (Principe, IX), os umori estão perfeitamente em ação.

A identificação do peculiar principado civil com a república permite entrever uma unidade entre ambos. O que faz um regime ser republicano, em seu fundamento principal, é o fato de os humores estarem ativos. Não apenas os tumultos fazem que um regime seja republicano, mas isso ainda se correlaciona com a liberdade (INGLESE, 1992, p. 27; SKINNER, 1999, p. 304; NADEAU, 2003). Une-se, assim, a política ao conflito dos humores, à liberdade e à república. A tarefa do príncipe é a neutralização dos humores que existem em todas as cidades, a das repúblicas, é inflá-los. Dessa tensão dos humores nascem três coisas: principado, liberdade ou licença (Principe, IX). O primeiro é quando um dos humores se sobressai ao outro, ou o do povo ou o dos grandes; o segundo é quando os humores se equilibram; o terceiro é quando a cidade cai na ruína. Quando nenhum dos lados se sobrepõe ao outro, há liberdade, por isso, a liberdade é inerente ao conflito e seu sustentáculo, do contrário, quando há vencedores, 
institui-se uma ordem absoluta (ordine assoluta) e não civil (civile) (Principe, IX, 23; INGLESE, 1992, p. 28).

Todo esse arcabouço teórico parte da premissa de que a política não possui determinações externas às ações humanas, e, justamente por isso, ela não é necessária, mas contingente. Esse caráter contingencial se reflete na dinâmica dos humores e, a partir dele, nos permite retomar a contribuição de Sasso. Um dos pontos que ele identifica com muita precisão é que quando não há leis, ordens e realidade social compatíveis, os tumultos geram corrupção e violência (SASSO, 1993, p. 175). Todavia, o comentador se mostra bastante comedido em avançar seu modelo interpretativo para a esfera estatal ao atribuir a possibilidade de tal compatibilidade a acontecimentos acidentais (SASSO, 1993, p. 176-179). Se, de fato, essa é uma marca da história florentina, ela não pode ser generalizada, justamente pelo fato de que a potência dos tumultos pode ser absorvida pelo próprio Estado sob circunstâncias diversas das daquela cidade.

A unidade conceitual do Stato como instrumento de força (ESPOSITO, 1984, p. 198), mas também de legitimação dos conflitos através das leis, não traz o imperativo da existência do tumulto institucionalizado. Para ensejar tal assertiva, Maquiavel parte do realismo político (BIGNOTTO, 1991, p. 94). Um dos menores e, sem dúvida, mais intrigantes capítulos de $\mathrm{O}$ Príncipe, o $\mathrm{XV}$, resume com maestria a versão da política do secretário de Florença. Nele são descritas duas formas de abordar o mundo político: a verdade efetiva (Príncipe, XV) e a imaginação (Principe, XV). A verdade efetiva é 
útil para quem a entende, vai direto à matéria, trata de um príncipe verdadeiro e é mais pertinente para a preservação do Estado, trata de como se vive e afirma, a partir da necessidade, que o príncipe deve ser bom ou não bom. Todas essas características afirmam uma versão da política na qual ela se põe na realidade histórica. A imaginação consiste em uma descrição das cidades que nunca foram vistas nem conhecidas, o príncipe é imaginado, trata de como se deveria viver, leva o Estado à ruína e afirma que o bom deve sempre ser feito (Principe, XV). A primeira trata da política, a segunda da moral (BIGNOTTO, 1991, p. 96; CHABOD, 1958, p. 182; SKINNER, 1996, p. 140). A conhecida distinção encontra não uma aplicação, mas uma reflexão conceitual e teórica. A moral existe - porque existem o bom e o não bom - mas não é critério para a política (CHABOD, 1958, p. 1).

Parece haver uma contradição interna na caracterização da imaginação. Uma cidade - república ou principado - nunca vista é o lugar onde se é bom, o que pode significar que agir bondosamente em todas as situações é apenas possível num lugar inexistente ${ }^{6}$. Primeiramente, isso marca o fato de que a bondade existe (Principe, XV) tanto na verdade efetiva, quanto na imaginação, mas na primeira apenas quando a necessidade exige. Por isso, não há contradição, no lugar imaginado não há necessidade, na verdade efetiva há necessidade, uma vez que há realização histórica (Principe, XV). Portanto, é a necessidade que marca a diferença e, consequentemente, a definição do realismo político (STRAUSS, 1978, p. 218; SKINNER, 1996, p. 153). Onde a necessidade impera, a política e a moral

\footnotetext{
${ }^{6}$ Tal interpretação implica no imperativo de que a bondade plena somente se constitui e pode ser percebida fora do universo político.
} 
se distanciam. É justamente no reconhecimento da necessidade que Maquiavel aloca as duas funções centrais dos Estados: as leis e as armas. Contudo, o problema permanece: como um príncipe pode ser capaz de, invariavelmente submetido à necessidade, permanecer equilibrado entre os dois humores sem descuidar das funções militares do Estado?

Federico Chabod (1958, p. 49) sugeriu que o caráter individual do príncipe não danifica sua capacidade centralizadora dos ditames do Estado: "O governo era essencialmente pessoal”. Uma vez que a figura do príncipe sintetiza as funções estatais e, fundamentalmente, oblitera os humores em, pelo menos, sete situações acima descritas, o papel político do príncipe em um principado que pode ser tratado como república se torna, no mínimo, limitado (RENAUDET, 1964, p. 245-258). Aqui, a comparação com os Discursos sobre a primeira década de Tito Livio ${ }^{7}$ se faz pertinente.

Comumente reconhecido como a verdadeira obra republicana de Maquiavel, os Discorsi seguem os dois paradigmas aqui apresentados através de $O$ Príncipe. O primeiro é o realismo político, o segundo, o conflito dos humores (STRAUSS, 1978, p. 46) correlatamente à política (CHABOD, 1958, p. 91). De fato, o viver político aparece no texto de um modo positivo e sempre oposto à corrupção (Discorsi, I, 6, 8; Discorsi, I, 6, 33; Discorsi, I, 18, 27; Discorsi, I, 25, 6; Discorsi, II, proemio, 9), mas o Stato reúne as características centrais para a definição da política, o lugar onde os humores se realizam. A peculiaridade do regime republicano não se limita ao governo misto, é

\footnotetext{
7 As seguintes abreviaturas serão usadas para referenciar tal obra:1. Discorsi, quando no texto; 2. Discorsi, seguida do livro e do capítulo quando em nota no corpo do texto ou como referência bibliográfica, como fora mencionado anteriormente.
} 
necessário que os humores estejam em ação. Assim, o conflito (tumulto) entre as duas vontades distintas carrega consigo duas consequências: a liberdade e a grandeza.

Afirmo que aqueles que identificam os tumultos entre os nobres e a plebe me parece censurarem as coisas que foram a primeira causa da sustentação da liberdade de Roma, e que consideram mais os rumores e a gritaria que destes tumultos nasciam do que os bons efeitos que eles geravam, e não consideram que em toda cidade há dois humores, aquele do povo e aquele dos grandes, e que todas as leis que se fazem em favor da liberdade nascem da desunião deles (Discorsi, I, 4; Tradução nossa.) ${ }^{8}$.

A constatação da existência em todas as cidades de dois humores (Discorsi, I, 4) significa que apenas a república bem-ordenada é capaz de absorvê-los parcialmente (BIGNOTTO, 1991, p. 85-86). Pelo impedimento de cada humor se realizar plenamente sem que o outro seja sufocado, é que a tensão conflituosa se torna necessária, daí a liberdade. Contudo, os conflitos devem sempre se limitar aos espaços políticos de atuação, de modo que não decaiam em violência física (STRAUSS, 1978, p. 243). Um exemplo da falha da política e precipitação da guerra está em História de Florença ${ }^{9}$.

As graves e naturais inimizades que há entre os homens populares e os nobres, causadas pela vontade destes

\footnotetext{
8 "Io dico che coloro che dannono $i$ tumulti intra $i$ Nobili e la Plebe mi pare che biasimino quelle cose che furono prima causa del tenere libera Roma, e che considerino più a' romori e alle grida che di tale tumulti nascevano, che a' buoni effetti che quelli partorivano; e che e' non considerino come e' sono in ogni republica due umori, quello del popolo e quello de' grandi; e come tutte le leggi che si fanno in favore della libertà, nascano dalla disunione loro".

9 Para a obra História de Florença, a seguinte referência será utilizada quando em nota no corpo do texto: Istorie Fiorentine, seguida do livro e do capítulo.
} 
de comandar e daqueles de não obedecer, são causa de todos os males que nascem nas cidades, porque desta diversidade de humores nutrem-se todas as coisas que perturbam as repúblicas. Isto manteve Roma desunida, isto, se é lícito comparar coisas pequenas com as grandes, tem dividido Florença: ocorre que os efeitos gerados em uma e outra cidade são diferentes, porque as inimizadas que foram no princípio de Roma entre o povo e os nobres causavam disputas, aquela de Florença, causava combates. Em Roma, as disputas terminavam com leis, em Florença, com exílio e com a morte de muitos cidadãos (Istorie Fiorentine, III, 1 ; tradução nossa. $)^{10}$.

Somente se torna contraditória a comparação da passagem dos Discorsi com a da História de Florença se não forem observadas as diferenças contidas nos casos analisados. Ambos os textos descrevem os tumultos entre os nobres e o povo, mas as conclusões são invariavelmente distintas (BOCK, 1999). Nos Discorsi, o conflito leva à liberdade e à grandeza, e na História de Florença, à guerra e à derrocada. A diferença marcante nas duas obras, como assinalada por Sasso, é que os conflitos podem ou não fazer parte das instituições políticas. No exemplo de Roma, os conflitos estão inseridos no Estado, em suas instituições políticas (DOTTI, 1979, p. 11; STRAUSS, 1978, p. 94; INGLESE, 1992, p. 44), já em Florença as disputas ganham as ruas, pois não têm espaço para serem desafogadas no

\footnotetext{
10 "Le gravi e naturali nimicizie che sono intra gli uomini popolari e $i$ nobili, causate da il volere questi comandare e quegli non ubbire, sono cagione di tutti $i$ mali che nascano nelle città, perché da questa diversità di umori tutte l'altre cose che pertubano le republiche prendono il nutrimento loro. Questo tenne disunita Roma; questo, se gli è lecito le cose piccole alle grandi agguagliare, ha tenuto diviso Firenze: avvenga che nell'una e nell'altra città diversi effetti partorissero, perché le nimicizie che furono nel principio in Roma intra il popolo e i nobili, disputando, quelle di Firenze, combatendo, si difinivano; quelle di Roma con una legge, quelle di Firenze con lo esilio e con la morte di molti cittadini terminavono".
} 
seio estatal. Compreende-se, com isso, que os tumultos são uma potência de liberdade e grandeza ou de guerra e ruína. Cabe, pois, às ordens colocar os conflitos em seus devidos lugares:

Verdadeira coisa é que algumas divisões prejudicam as repúblicas e outras as ajudam. Aquelas que são prejudiciais vêem acompanhadas de facções e partidários, as que ajudam se mantém sem facção e sem partidários. Portanto, quem funda uma república, como não pode evitar que nela haja inimizades, deve evitar pelo menos que não haja facções (Istorie Fiorentine, VII, 1; tradução nossa. $)^{11}$.

O esforço republicano é, portanto, o de institucionalizar o conflito dos humores de tal maneira que as leis sejam sempre respeitadas. Este processo pode ser identificado com as ordens (ordini). Como resultado do conflito institucionalizado, o governo pelas leis se apresenta como uma característica central da república e, nesse sentido, se diferencia dos principados (BIGNOTTO, 1991, p. 106; SKINNER, 1996, p. 145).

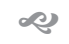

A contribuição de Sasso mostra com brilhantismo as condições históricas que condicionam os elementos positivos e negativos do conflito, mas, ao optar por restringir a análise às duas repúblicas - Roma e Florença -, acabou por deixar para segundo plano o papel da centralidade do poder. Essa

\footnotetext{
${ }_{11}$ "Vera cosa è che alcune divisioni nuocono alle republiche e alcune giovono. Quelle nuocono che sono dalle sètte e da partigiani accompagnate, quelle giovano che sanza sètte e sanza partigiani si mantengano. Non potendo adunque provvedere uno fondatore di una republicha che non sieno inimicizie in quella, ha a provvedere almeno che non vi sieno sètte".
} 
perspectiva republicana, autorizada pelo próprio Maquiavel nas primeiras frases do nono capítulo de O Príncipe, arremata o tema. Por motivos diversos, entre os capítulos II e VIII, o príncipe não se apresenta como ator político que se coloca como parte da dinâmica da cidade, porque oblitera seus humores. Por outro lado, também não possui uma participação ativa no principado civil, visto que foi apenas escolhido por um dos humores e, por isso, está submetido a ele. Em qualquer dos casos, o príncipe deve manter os humores adormecidos se desejar se manter no poder.

A disjunção entre poder estatal e atividade dos humores é, em si mesma, a estratégia que rege a dominação do príncipe. Opostamente, as repúblicas que não exercitam habilidosamente o poder estatal fracionam de tal maneira os humores que estes se multiplicam e decaem na disputa violenta e fratricida. Quando, por fim, a cidade tem seus humores latentes e um Estado capaz de absorvê-los sem multiplica-los, nenhum outro regime é possível senão a república.

\section{Referências}

BARON, Hans. "Querelle of Ancients and Moderns". In: KRISTELLER, P. O.; WIENER, P. P. (Ed.). Renaissance Essays. New York: University of Rochester Press, 1992.

BERARDI, Felice Antonio. La concezione dello Stato in Bodin, Machiavelli, Kant, Hegel e Marx. Lanciano: Rivista Abruzzese, 1975.

BIGNOTTO, Newton. Maquiavel republicano. São Paulo: Loyola, 1991. 
BOCK, Gisela. "Civil discord in Machiavelli's Istorie Fiorentine”. In: BOCK, G.; SKINNER, Q.; VIROLI, M. (Org.). Machiavelli and republicanism. Cambridge: Cambridge University Press, 1999.

CHABOD, Federico. Machiavelli and the renaissance. Translated by David Moore. New York: Harper \& Row publishers, 1958.

DOTTI, Ugo. Niccolò Machiavelli: la fenomenologia del potere. Milano: Feltrinelli Editore, 1979.

ESPOSITO, Roberto. Ordine e conflito: Machiavelli e la letteratura politica del rinascimento italiano. Napoli: Liguori Editore, 1984.

INGLESE, Giorgio. "Il Principe (De Principatibus)" di Niccolò Machiavelli. Torino: Einaudi, 1992.

LEFORT, Claude. As formas da história. São Paulo: Editora Brasiliense, 1979. . Le travail de l'oeuvre: Machiavel. Paris: Gallimard, 1986.

MACHIAVELLI, Niccolò. Discorsi sopra la prima deca di Tito Livio. A cura di Giorgio Inglese. Milano: BUR, 2010.

. Il Principe. A cura di Giorgio Inglese. Torino: Einaudi, 1996.

. Opere. A cura di Corrado Vivanti. Torino: Einaudi, 1997. (3 vol.) 
MANSFIELD, Harvey Claflin. Machiavelli's virtue. Chicago: University of Chicago Press, 1998.

NADEAU, Christian. "Machiavel: Domination et liberté politique”. Philosophiques, Vol. 30, n. 2, p. 321-351, 2003.

RENAUDET, Augustin. Maquiavelo. Traducción de Francisco Díez Del Corral y Daniele Lacascade. Madrid: Editorial Tecnos, 1964.

RUBINSTEIN, Nicolai. "Machiavelli and florentine republican experience”. In: BOCK, G.; SKINNER, Q.; VIROLI, M. (Org.). Machiavelli and republicanism. Cambridge: Cambridge University Press, 1999.

SASSO, Gennaro. Machiavelli: la storiografia. Bologna: Il Molino, 1993.

SKINNER, Quentin. As Fundações do Pensamento Político Moderno. Tradução de Renato Janine Ribeiro e Laura Teixeira Motta. São Paulo: Companhia das Letras, 1996.

. "The republican ideal of political liberty". In: BOCK, G.; SKINNER, Q.; VIROLI, M. (Org.). Machiavelli and republicanism. Cambridge: Cambridge University Press, 1999.

STRAUSS, Leo. Thoughts on Machiavelli. 2. ed. Chicago: Chicago University Press, 1978.

VIROLI, Maurizio. "Machiavelli and the republican idea of politics”. In: BOCK, G.; SKINNER, Q.; VIROLI, M. (Org.). Machiavelli and republicanism. Cambridge: Cambridge University Press, 1999. 